\title{
EVALUATION OF EXPOSURE TO ELECTROMAGNETIC RADIOFREQUENCY RADIATION IN THE INDOOR WORKPLACE ACCESSIBLE TO THE PUBLIC BY THE USE OF FREQUENCY-SELECTIVE EXPOSIMETERS
}

\section{KRZYSZTOF GRYZ, JOLANTA KARPOWICZ, WIESŁAW LESZKO, and PATRYK ZRADZIŃSKI}

Central Institute for Labour Protection - National Research Institute, Warszawa, Poland

Laboratory of Electromagnetic Hazards

\begin{abstract}
Objectives: The aim of the study was to identify and assess electromagnetic radiofrequency radiation (EMRR) exposure in a workplace located in a publicly accessible environment, and represented by offices (where exposure is caused by various transmitters of local fixed indoor and outdoor wireless communication systems). Material and Methods: The investigations were performed in 45 buildings (in urban and rural areas in various regions of Poland), using frequency-selective electric field strength (E-field) exposimeters sensitive to the EMRR with a frequency range of 88-2500 MHz, split into 12 subbands corresponding to the operating frequencies of typical EMRR sources. The variability of the E-field was analyzed for each frequency range and the total level of exposure by statistical parameters of recorded exposimetric profiles: minimum, maximum, median values and 25-75th - percentiles. Results: The main sources of exposure to EMRR are mobile phone base transceiver stations (BTS) and radio-television transmitters (RTV). The frequency composition in a particular office depends on the building's location. The E-field recorded in buildings in urban and rural areas from the outdoor BTS did not exceed respectively: medians -0.19 and $0.05 \mathrm{~V} / \mathrm{m}, 75$ th percentiles -0.25 and $0.09 \mathrm{~V} / \mathrm{m}$. In buildings equipped with the indoor BTS antennas the E-field did not exceed: medians $-1 \mathrm{~V} / \mathrm{m}, 75$ th percentiles $-1.8 \mathrm{~V} / \mathrm{m}$. Whereas in urban and rural areas, the median and 75th percentile values of the E-field recorded in buildings located near the RTV (within $1 \mathrm{~km}$ ) did not exceed: 1.5 and $3.8 \mathrm{~V} / \mathrm{m}$ or 0.4 and $0.8 \mathrm{~V} / \mathrm{m}$, for radio FM band or for TV bands, respectively. Conclusions: Investigations confirmed the practical applicability of the exposimetric measurements technique for evaluating parameters of worker's exposure in both frequency- and time-domain. The presented results show EMRR exposure of workers or general public in locations comparable to offices to be well below international limits.
\end{abstract}

Key words:

Occupational exposure, Measurements, Electromagnetic fields, Exposure pattern

\footnotetext{
This paper has been based on the results of a research task (II.B.07) carried out within the scope of the 2nd stage of the National Programme "Improvement of safety and working conditions" partly supported in 2011-2013 - within the scope of research and development - by the Ministry of Science and Higher Education/National Centre for Research and Development in Poland. Main co-ordinator: The Central Institute for Labour Protection - National Research Institute.

Received: March 25, 2014. Accepted: June 19, 2014.

Corresponding author: K. Gryz, Central Institute for Labour Protection - National Research Institute (CIOP-PIB), Czerniakowska 16, 00-701 Warszawa, Poland (e-mail:krgry@ciop.pl).
} 


\section{INTRODUCTION}

Almost everyone experiences some exposure to electromagnetic fields of various frequencies caused by the use of electrical devices and wireless communication systems. The common component of that exposure comes from electromagnetic radiofrequency radiation (EMRR) of various frequencies from the frequency band ranging from 88 to $5700 \mathrm{MHz}$, emitted by various systems of modern wireless technologies, such as radio and television broadcasting, public cellular mobile communication systems or wireless access to the Internet. The use of such systems causes common exposure to EMRR present in both work environment and public spaces. The frequency composition and level of environmental EMRR is still influenced by changes in wireless technologies in use, and the number of emitting devices being in use in a particular area.

Serious acute health effects of high-level exposure to EMRR, usually present only in the workplace or medical use, are well known and recognised as related to the thermal effects of electromagnetic energy absorption in the human body [1-3]. Evaluation of EMRR emissions from the sources existing in public and work environment is an important element of the systematic management of electromagnetic hazards [3-6]. Exposure limits are mostly provided with regard to electric field strength $(\mathrm{E})$ expressed in volts per metre $(\mathrm{V} / \mathrm{m})$, because general public exposure can usually be qualified as 'far field exposure.' In some workplaces, however, located in the 'near-field' very close to a source of EMRR, it is also necessary to evaluate magnetic field strength $(\mathrm{H})$ expressed in amperes per metre $(\mathrm{A} / \mathrm{m})[3,4]$.

Investigations regarding a possible correlation between adverse health effects and chronic exposure, e.g., through epidemiological studies, constitute another reason for monitoring EMRR exposure patterns. Ubiquitous longterm exposure to low levels of EMRR from wireless communication emitters (frequently belonging to new and emerging technologies) is a relatively new environmental factor. Scientific knowledge on the health effects of such exposure is still limited. Even though the health effects of exposure to radiation from mobile phone systems is the topic which is most deeply explored, the results of these investigations are still inconclusive [2,7-12].

The most widely used classic measurement technique for electromagnetic environmental hazards involves broadband measurements of electric or magnetic field strengths in selected places (i.e., spot measurements). However, they do not provide data appropriate for identifying dominant sources of EMRR exposure to particular persons. Over the last decade, a new and still developing investigation method has been applied in the field of EMRR studies the use of body-worn (pocket-sized), frequency-selective personal exposure meters (known as exposimeters). These allow many-hour (even many-day) measurements (recordings) of the pattern of individual exposure to EMRR (exposimetric profile) - covering the variability of exposure level over the time of recording, which is caused by the person's movements or changes in the operation of EMRR sources [13,14].

Exposimeters of EMRR, or more precisely E-field exposimeters, are dedicated for investigations of electromagnetic hazards caused by various wireless telecommunication systems located in both working and living environment. The main goal behind the design of such devices was to enable the study on the relationship between parameters of exposure of individual persons and their activities, when looking at contributions from various sources, excluding the exposure that comes from the personal use of mobile phone handsets. The localised exposure of hand and head (caused by the normal use of a mobile phone) has to be assessed in a different way - by the electromagnetic energy absorption level, usually estimated from numerical calculations $[3,4]$.

However, exposimeters may also be used in another way to examine the parameters of EMRR exposure in selected 
locations, including the variability of exposure over many hours of recordings (monitoring). Data presented in the article was collected over 2011-2013, in broader studies aiming at introducing this new investigation technique to Poland, through a systematic study on the metrological properties of frequency-selective exposimeters, and the relationship between the results of exposimetric investigations and unperturbed EMRR in the case of various ways of using exposimeters $[15,16]$.

\section{AIM OF THE STUDY}

The aim of the study was to apply the frequency-selective, pocket-sized exposimeters to identify and assess EMRR exposure in the workplace located in a publicly accessible environment and represented by offices (where various fixed transmitters of local indoor wireless communication systems and outdoor wireless communications systems located at varied distances contribute to the total EMRR level).

\section{MATERIAL AND METHODS}

The study regarding EMRR exposure inside various public buildings located in urban and rural areas was performed by the use of frequency-selective exposimeters.

The many-hours investigations of the EMRR exposure pattern were performed using frequency-selective exposimeters EME SPY 121 (Satimo, Brest, France). They are portable, pocket-sized, battery supplying EMRR data loggers of the root-mean-square (RMS) actual value of the E-field, with dimensions of $193 \times 96 \times 70 \mathrm{~mm}$ and a weight of 450 g. Frequency-selective EMRR exposure evaluation is achievable due to the frequency response of exposimeters split into 12 pre-defined frequency measurement ranges, corresponding to the most common EMRR applications currently in use in the public environment (Table 1). The typical locations of various kinds of EMRR sources are also given in Table 1.

Table 1. Predefined measurement frequency bands of the used SPY 121 exposimeters, and typical locations of EMRR sources (outdoor or indoor for locations of performed investigations)

\begin{tabular}{lcll}
\hline \multicolumn{1}{c}{ Label } & $\begin{array}{c}\text { Frequency band } \\
(\mathrm{MHz})\end{array}$ & \multicolumn{1}{c}{ Use of frequency bands } & \multicolumn{1}{c}{$\begin{array}{c}\text { Location of EMRR } \\
\text { source }\end{array}$} \\
\hline FM & $88-108$ & FM radio broadcasting & outdoor (A) \\
TV3 & $174-233$ & TV VHF band broadcasting & outdoor (A) \\
Tetra & $380-400$ & mobile communications system for closed groups & outdoor (TC) \\
TV4\&5 & $470-830$ & TV UHF band broadcasting & outdoor (A) \\
GSM 900 (UL) & $880-915$ & digital cellular network - transmission from handset to BTS & indoor (TC) \\
GSM 900 (DL) & $925-960$ & digital cellular network - transmission from BTS to handset & outdoor or indoor (A) \\
DCS 1800 (UL) & $1710-1785$ & digital cellular network - transmission from handset to BTS & indoor (TC) \\
DCS 1800 (DL) & $1805-1880$ & digital cellular network - transmission from BTS to handset & outdoor or indoor (A) \\
DECT & $1880-1900$ & digital enhanced cordless telecommunications of short distance & indoor (TC) \\
UMTS (UL) & $1920-1980$ & digital cellular network - transmission from handset to BTS & indoor (TC) \\
UMTS (DL) & $2110-2170$ & digital cellular network - transmission from BTS to handset & outdoor or indoor (A) \\
WLAN/WiFi 2G & $2400-2500$ & wireless local area network, e.g., access to internet & outdoor or indoor (TC) \\
\hline
\end{tabular}

EMRR - electromagnetic radiofrequency radiation; FM - frequency modulation; TV - television; Tetra - terrestrial trunked radio; GSM - global system for mobile communications; DCS - digital communication system; DECT - digital enhanced cordless telephony; UMTS - universal mobile telecommunications system; WLAN/WiFi - wireless local area network / wireless fidelity; TV VHF - very high frequency television; TV UHF - ultra high frequency television; BTS - base transceiver station; DL - down link; UL - up link; A - included in the detailed analysis of results (Figures 3-9); $\mathrm{TC}-$ contributing in the total value according to formula 1 (Figures 3-10). 
Total level of exposure registered by the exposimeters represents the broadband measurement results covering each frequency components, according to the formula:

$$
\mathrm{E}_{\text {total }}=\sqrt{\sum \mathrm{E}_{\mathrm{i}}^{2}}
$$

where:

$\mathrm{E}_{\mathrm{i}}$ - electric field strength recorded in a predefined frequency range, e.g., $\mathrm{E}_{\mathrm{FM}}, \mathrm{E}_{\mathrm{TV} 3}, \mathrm{E}_{\text {Tetra }}, \mathrm{E}_{\mathrm{GSM} 900(\mathrm{UL})}, \mathrm{E}_{\mathrm{GSM} 900(\mathrm{DL})}$, etc.

The measurement range of the exposimeters in each individual frequency band is $0.05-10 \mathrm{~V} / \mathrm{m}$. The exposimeters are equipped with a memory of $12.5 \mathrm{k}$ samples, which can be filled up by E-field recordings with a programmable sampling rate of 4-255 $\mathrm{s}$ and actual real time attached to each E-field sample.

The investigations were performed during workers' common activities. The exposimeters were located at the distance of $1 \mathrm{~m}$ from the worker's seat in the investigated workplace with the aim of limiting 'shadow effects' caused by reflections and absorptions of electromagnetic radiation by the human body [16]. EMRR were recorded over 1-24 h with a sampling rate depending on the duration of measurements: $4 \mathrm{~s}$ in the case of recordings shorter than $14 \mathrm{~h}$, or $6 \mathrm{~s}$ in the case of recordings lasting whole day. The measurement results were analysed in the following frequency bands that correspond to the most common components of public exposure to EMRR from the fixed transmitters, i.e., FM radio, TV3, TV4\&5 $5^{1}$ analogue and digital television, BTS of wireless communication GSM, DCS, UMTS and WLAN/WiFi.

Identification of sources of EMRR found in each workplace was also done more precisely by using a spectrum analyser - SRM 3000 (Narda, Pfullingen, Germany). The SRM 3000 analyser enables broadband or selective measurements of EMRR. The SRM 3000 measures the RMS value of E-field strength in the measurement range from $0.2 \mathrm{mV} / \mathrm{m}$ to $200 \mathrm{~V} / \mathrm{m}$ in the whole frequency

${ }^{1}$ TV4\& 5 band covers TV band 4 and TV band 5 (UHF - ultra high frequency). band, i.e., $27 \mathrm{MHz}-3 \mathrm{GHz}$, or adjustable sub-bands. The mode of work in the function of spectrum analysis of the measured EMRR signal is also enabled.

\section{Statistics}

Data stored in the memory of frequency-selective exposimeters EME SPY 121 were transferred to the computer in text format files and analysed using the exposimeter's firmware (EME SPY Analysis v. 3.06) and software package - Statistica, Version 10.0 PL (StatSoft, USA). The variability of the level of worker's exposure to the E-field was analysed by calculating statistical parameters of registered exposimetric profiles: minimum, maximum and median values, and interquartile range (IQR) between the 25-75th percentiles - from profiles registered in each frequency range and the total level of exposure.

\section{RESULTS}

Investigations of EMRR exposure have been performed in 45 locations, split into sub-groups of a workplace located inside buildings in urban (cities with 30 000-1 600000 inhabitants) and rural (cities below 30000 inhabitants) areas. In urban areas 19 recordings were made - 5 near the RTV transmitters (at a distance up to $1 \mathrm{~km}$ ), 14 far from the RTV transmitters (at a distance exceeding $2 \mathrm{~km}$ ). In urban areas, 5 out of 14 recordings were performed inside buildings equipped with the indoor BTS antennas. In rural areas 26 recordings were made -5 near the RTV transmitters and 21 far from the RTV transmitters (the criterion of classifying the place of measurements was the same as mentioned for urban areas). The spectrum analysis of EMRR showed a different frequency composition of radiation, depending on the kind of measurement area - inside buildings located at various distances from the transmitters of wireless communications systems (Figure 1 and 2). Figures 3-9 present contribution of various 
types of EMRR sources into the exposimetric profiles recorded in buildings located at various distances from the fixed RTV and BTS antennas (recorded in 6 frequency bands) and the total values of exposure recorded over all 12 frequency bands (according to formula 1). The dominant recorded EMRR were emitted by the outdoor sources for the investigated buildings (e.g., FM and TV broadcasting antennas) or by both - outdoor and indoor sources for buildings (e.g., indoor transmitting antennas of mobile communication system or local wireless internet access).

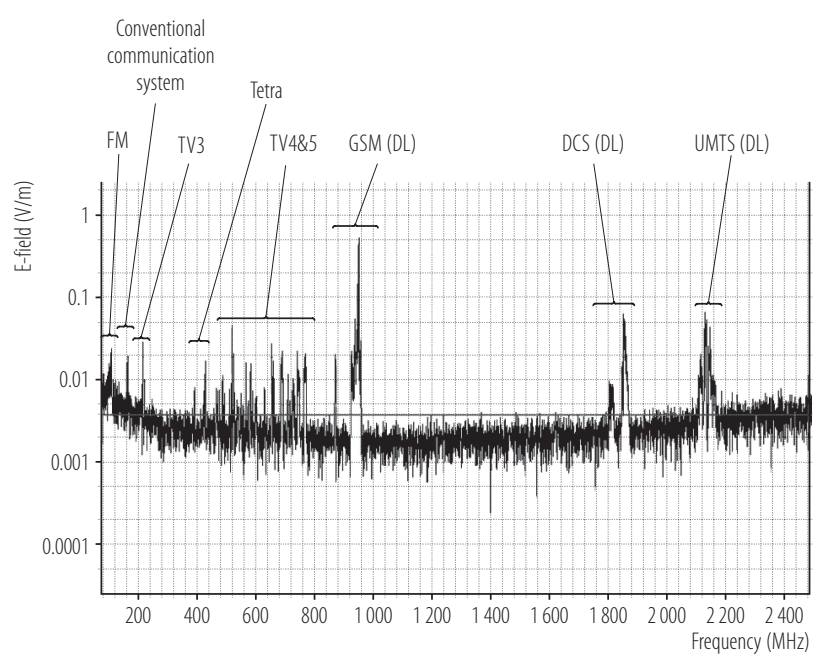

Abbreviations as in Table 1.

Fig. 1. Examples of EMRR frequency spectrum recorded in buildings in urban areas

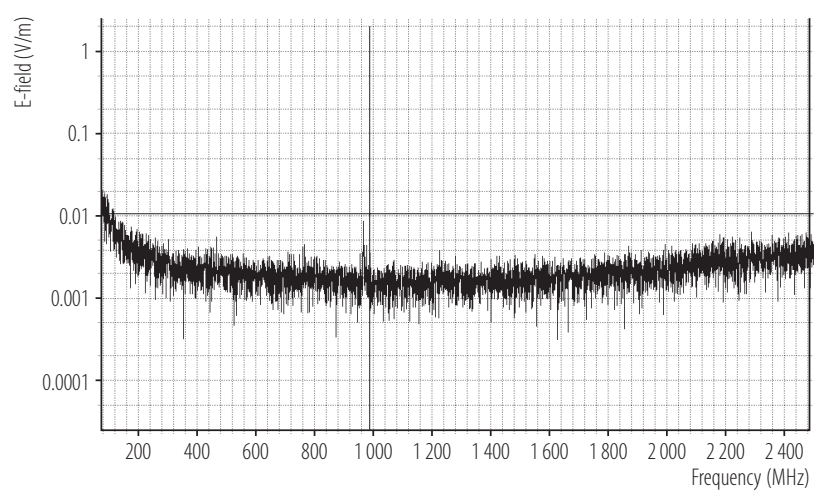

Fig. 2. Examples of EMRR frequency spectrum recorded in buildings in rural areas

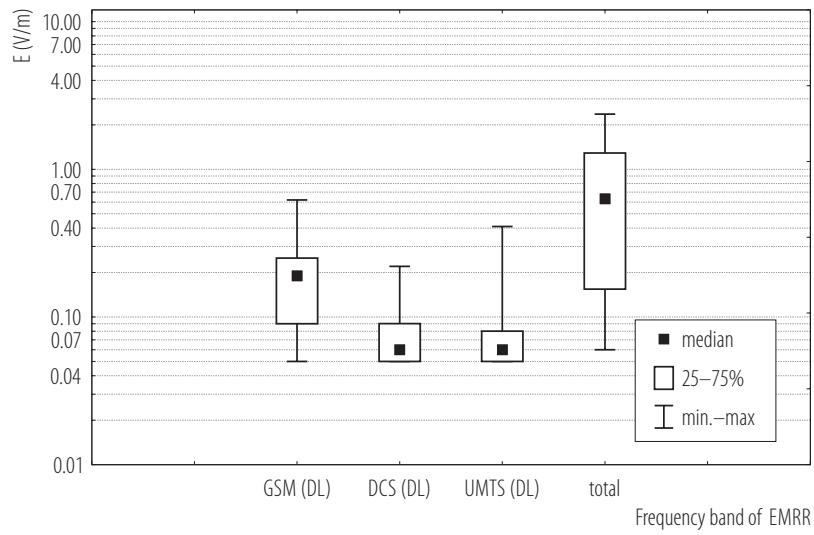

Total - statistical parameters of results of broadband measurements from all outdoor and indoor sources for presented recordings. Abbreviations as in Table 1.

Fig. 3. Statistical parameters of E-field components from outdoor mobile phone BTS antennas, recorded inside buildings located in urban areas $(\mathrm{N}=14)$

The level of exposure is influenced by the distance from measurement location to the radiation source. Taking into account the medians and the IQR of recorded E-field exposure to EMRR of mobile communications BTS antennas - in urban areas exposure is higher than in the rural ones (75th percentile below: $0.25 \mathrm{~V} / \mathrm{m}$ and $0.07 \mathrm{~V} / \mathrm{m}$, respectively) (Figure 3 and 4). Although the output power of the indoor BTS antennas is lower (by just a few watts)

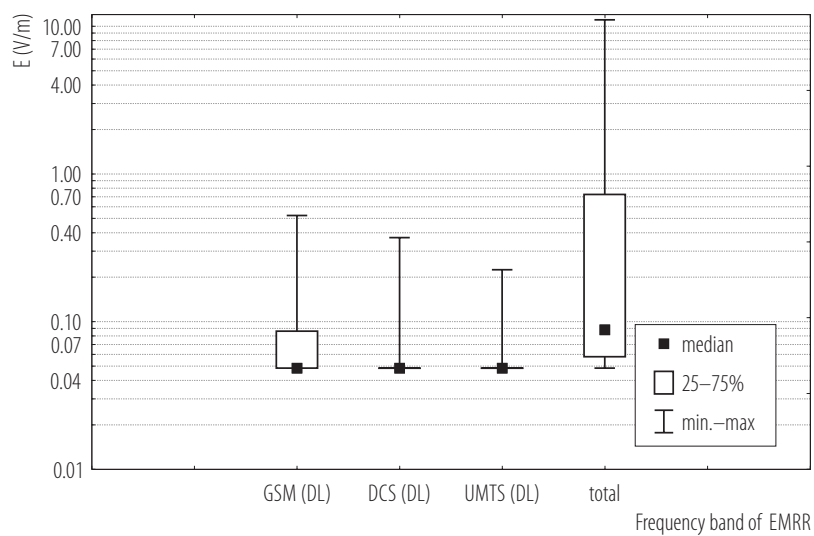

Abbreviations as in Table 1 and Figure 3.

Fig. 4. Statistical parameters of E-field components from outdoor mobile phone BTS antennas, recorded inside buildings located in rural areas $(\mathrm{N}=26)$ 


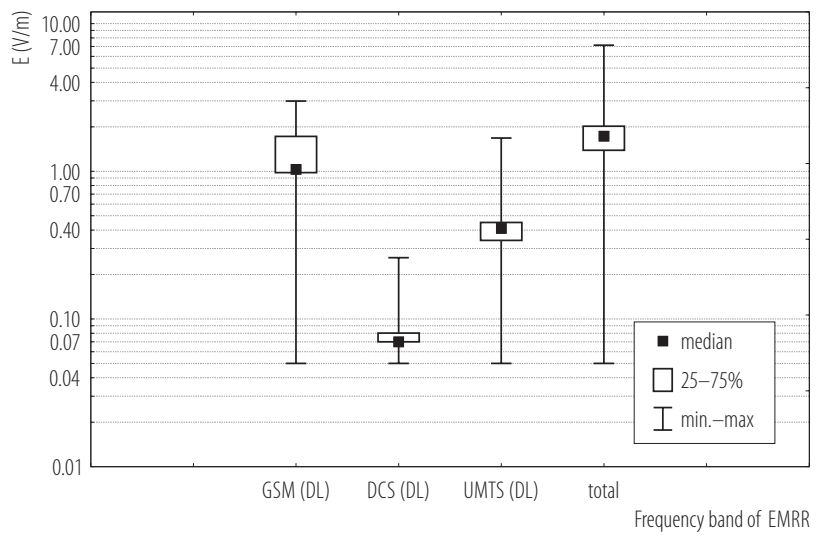

Abbreviations as in Table 1 and Figure 3.

Fig. 5. Statistical parameters of E-field components from indoor mobile phone BTS antennas, recorded inside buildings located in urban areas where BTS are in use $(\mathrm{N}=5)$

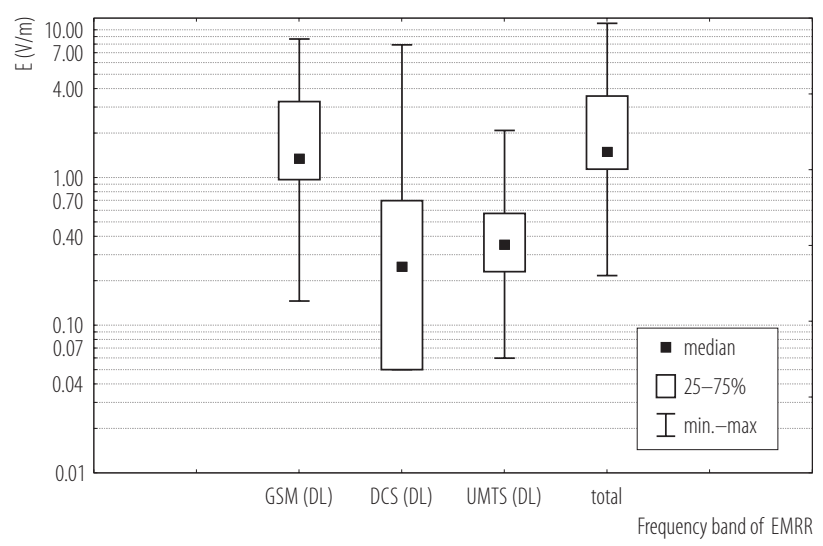

Abbreviations as in Table 1 and Figure 3.

Fig. 6. Statistical parameters of E-field components from FM radio and television broadcasting antennas, recorded inside buildings located at a distance up to $1 \mathrm{~km}$ from antennas in rural areas $(\mathrm{N}=5)$

in comparison to the output power of the outdoor BTS (of an order of tens watts) - in the buildings equipped with the indoor BTS antennas an increased level of exposure was recorded because of the significantly shorter distance (median of E-field up to $1.0 \mathrm{~V} / \mathrm{m}$, 75th percentile of E-field up to $1.8 \mathrm{~V} / \mathrm{m}$ ) (Figure 5).

The obtained results also showed that exposure to EMRR from the UMTS frequency range is lower than from the GSM range.

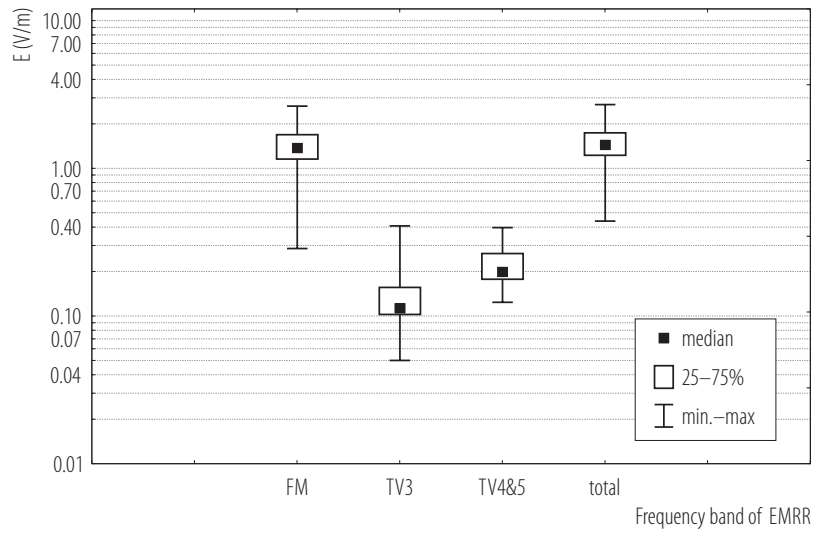

Abbreviations as in Table 1 and Figure 3.

Fig. 7. Statistical parameters of E-field components from FM radio and television broadcasting antennas, recorded inside buildings located at a distance up to $1 \mathrm{~km}$ from antennas in urban areas $(\mathrm{N}=5)$

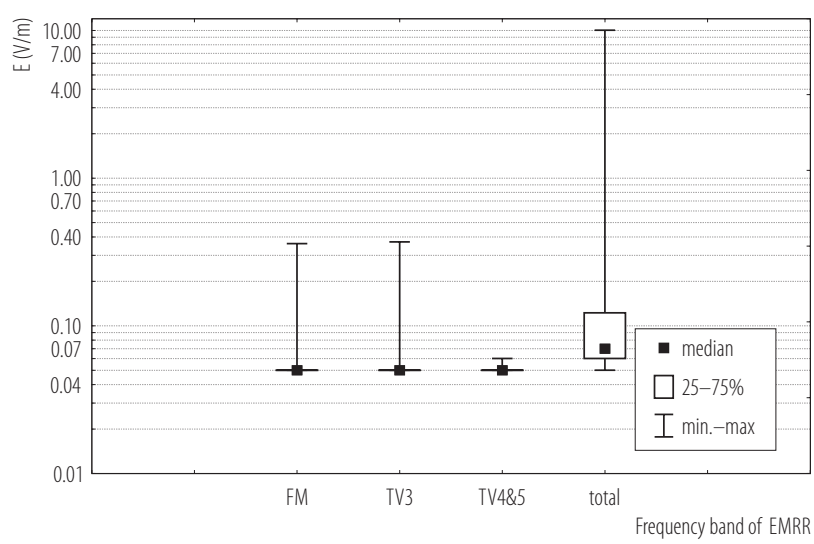

Abbreviations as in Table 1 and Figure 3.

Fig. 8. Statistical parameters of E-field components from FM radio and television broadcasting antennas, recorded inside buildings located at a distance exceeding $2 \mathrm{~km}$ from antennas in rural areas $(\mathrm{N}=21)$

Exposure to EMRR in offices located in urban and rural areas is similar when near the RTV transmitters (at a distance up to $1 \mathrm{~km}$ ). Medians and 75th percentile values of the recorded E-field in this case were, as follows: in the FM band up to 1.5 and $3.8 \mathrm{~V} / \mathrm{m}$, in the TV bands - up to 0.4 and $0.8 \mathrm{~V} / \mathrm{m}$ (Figure 6 and 7). A greater distance from the RTV transmitters moves exposure to EMRR to levels comparable with typical conditions in urban or rural areas (Figure 8 and 9). 


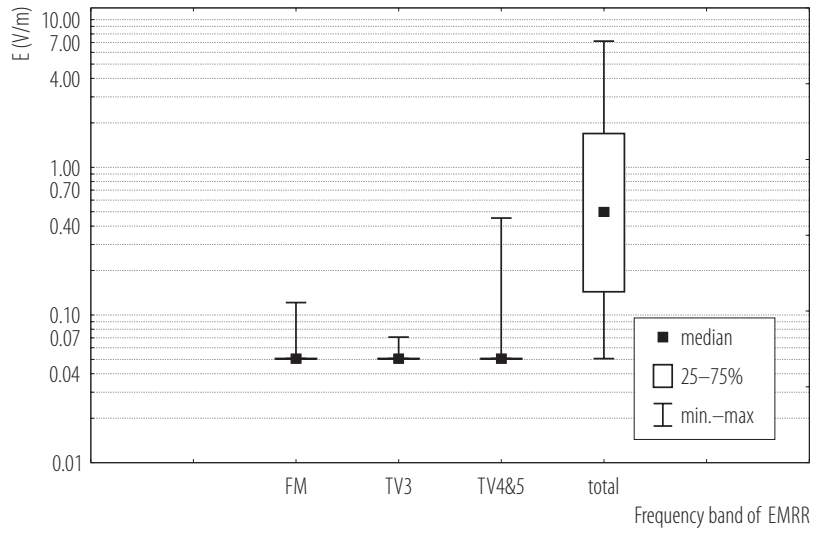

Abbreviations as in Table 1 and Figure 3.

Fig. 9. Statistical parameters of E-field components from FM radio and television broadcasting antennas, recorded inside buildings located at a distance exceeding $2 \mathrm{~km}$ from antennas in urban areas $(\mathrm{N}=14)$

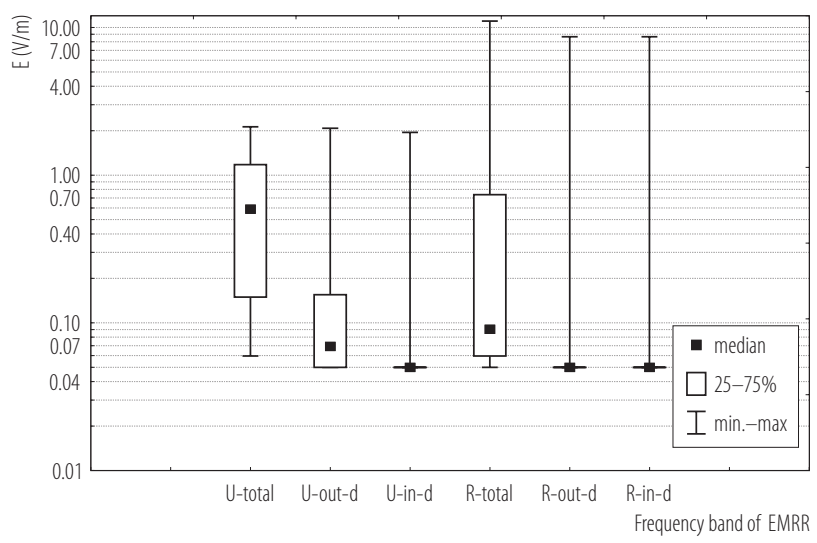

The results of broadband measurements from all outdoor and indoor sources (total) and fractions of this results split into subgroups covering contributions from only outdoor (out-d) or indoor (in-d) sources for investigated buildings.

Fig. 10. Statistical parameters of the E-field, representing complex exposure to EMRR, recorded inside buildings in urban $(\mathrm{U})(\mathrm{N}=14$, without cases with indoor BTS antennas) and rural $(\mathrm{R})(\mathrm{N}=26)$ areas

In the investigated office rooms in urban areas, the recorded exposure to EMRR from the outdoor sources is at least 1.5 times higher than in the rural areas (Figure 10). It needs to be pointed out that fraction of total (broadband) measurements results recorded at frequency bands representing exposure from the fixed indoor and outdoor transmitters is significantly lower than this total value (Figure 10). The reason of exposure from this gap between total values and indoor and outdoor components was caused by the EMRR emitted by handsets (mainly mobile or cordless phones). As mentioned before, this exposure needs to be evaluated in a different way than exposimetric measurements, and usually the users of handsets may control the pattern of its use in time, whereas the fixed transmitters covered by the presented study, are out of control of individual habitants.

\section{DISCUSSION}

The complex exposure to EMRR, in both working and living environment, is a result of the wide use of various wireless systems, mostly in telecommunications, e.g., FM radio, analogue and digital TV, wireless communication Tetra, GSM, DCS, UMTS. Frequency-selective exposimetric investigations of EMRR exposure had not been performed in Poland before the reported study. Even though, these investigations were performed in a working environment, the results also represent profiles of typical exposure in a living environment because the exposure to EMRR of workers and the general public present in a particular area is caused by the same EMRR sources (e.g., radio, television and mobile phone BTS transmitting antennas). The presented results also cover indoor EMRR exposure, which is a major part of daily exposure of both workers and the general public (lasting probably over $80 \%$ of daytime for the majority of the population).

A spectrum analysis of EMRR performed in the evaluated locations was helpful in interpreting the obtained exposimetric profiles, and avoiding any misinterpretation of them because of out-of-band sensitivity of the exposimeters. Narrow gaps between some of the predefined measurement bands of frequency-selective exposimeters enable the false identification of EMRR sources contributing to the measured signal. An example of such 
a misinterpretation is the detection of a DECT signal in the results of the influence of DCS (DL) or UMTS (UL) signals, in spite of the lack of DECT (cordless) phone systems in the investigated places.

Evaluations of environmental exposure to EMRR are organised within the frames established by the European directives on electromagnetic compatibility or workplace health and safety, as well as international and European standards, international guidelines on workers and general public protection against electromagnetic hazards, and the requirements of legislation established in particular countries [17-23]. As a result, exposure to EMRR is studied in the context of compliance with exposure limits regarding the safety of workers or the general public (Table 2) [17-23].

Table 2. Examples of EMRR environmental exposure limits

\begin{tabular}{|c|c|c|}
\hline Requirement & $\begin{array}{l}\text { Frequency } \\
(\mathrm{MHz})\end{array}$ & $\begin{array}{l}\text { Electric field strength } \\
(\mathrm{V} / \mathrm{m})\end{array}$ \\
\hline \multirow{3}{*}{$\begin{array}{l}\text { Council of the European Union Recommendation 1999/519/EC- } \\
\text { general public [17] }\end{array}$} & $10-400$ & 28 \\
\hline & $400-2000$ & $1.375 \mathrm{f}^{1 / 2}$ \\
\hline & $2000-300000$ & 61 \\
\hline \multirow[t]{3}{*}{ Directive 2013/35/EC - workers [18] } & $10-400$ & 61 \\
\hline & $400-2000$ & $3 \mathrm{f}^{1 / 2}$ \\
\hline & $2000-6000$ & 140 \\
\hline Poland - general public [19] & 3-300 000 & 7 \\
\hline \multirow[t]{3}{*}{ Belgium (Flemish) - general public [20] } & 900 & $21^{\mathrm{a}}$ \\
\hline & 1800 & $29^{\mathrm{a}}$ \\
\hline & 2100 & $31^{\mathrm{a}}$ \\
\hline \multirow[t]{2}{*}{ Italy - general public [21] } & 3-3000 & $\begin{array}{c}20^{\mathrm{b}} \\
6^{\mathrm{c}}\end{array}$ \\
\hline & $3000-300000$ & $\begin{array}{l}40^{\mathrm{b}} \\
6^{\mathrm{c}}\end{array}$ \\
\hline \multirow[t]{3}{*}{ Switzerland - general public [22] } & 900 & 4 \\
\hline & 1800 & 6 \\
\hline & 900 and 1800 & 5 \\
\hline \multirow[t]{3}{*}{ Turkey - general public [23] } & $10-400$ & $\begin{array}{c}7^{\mathrm{d}} \\
18^{\mathrm{e}}\end{array}$ \\
\hline & $400-2000$ & $\begin{array}{l}0.341 \mathrm{f}^{1 / 2, \mathrm{~d}} \\
1.375 \mathrm{f}^{1 / 2, \mathrm{e}}\end{array}$ \\
\hline & $2000-6000$ & $\begin{array}{l}15^{\mathrm{d}} \\
61^{\mathrm{e}}\end{array}$ \\
\hline
\end{tabular}

EMRR - electromagnetic radiofrequency radiation.

${ }^{\text {a }}$ For broadband spectrum of electromagnetic fields, from $100 \mathrm{kHz}$ to $300 \mathrm{GHz}$ (except TV and radio transmitters), including mobile phone stations. Per antenna $3 \mathrm{~V} / \mathrm{m}$ (900 MHz), 4.2 V/m (1800 MHz), 4.5 V/m (2100 MHz).

${ }^{\mathrm{b}}$ Exposure limits - cannot be exceeded under any circumstances.

${ }^{c}$ Attention value - cannot be exceeded in residential environment.

${ }^{\mathrm{d}}$ Limit value for single device.

${ }^{\text {e }}$ Total limit value for many devices. 
Special attention is needed in the case of particular groups that are more sensitive to the influence of EMRR, such as electronic active implants users or pregnant women [18]. The results of measurements performed in urban and rural areas confirmed that, also in Poland, the indoor exposure levels are usually significantly lower than the general public exposure limits provided by the international guidelines and legislation established in various countries [17-23]. Taking into account the presented evidence and the statement from the European Directive 2013/35/EU, in the indoor workplace accessible to the public, where exposure was shown to be compliant with general public limits, there is no further need for a detailed evaluation of its compliance with occupational limits [18].

However, it is also important to take into consideration the fact that, as a result of the limited evidence, it is not justified to ignore possible health hazards linked with EMRR exposure, and public concern over such health hazards remains high, including both: citizens and political level, expressed for example in the European Parliament resolutions [24]. The results of epidemiological investigations show that exposure to EMRR, even without exceeding international exposure limits, is statistically linked with more frequently diagnosed cancer diseases. This relationship was identified among people exposed over many years to EMRR as a result of professional activities or the use of mobile phones, though no consensus on the explanation of which mechanism of interaction between EMRR and human body is involved has been reached. On the basis of the available, though limited, evidence from epidemiological studies concerning the use of mobile phones, the International Agency for Research on Cancer classified EMRR as a possible human carcinogen (2B classification) [12]. However, due to the long-term latency of cancer diseases (even longer than 20 years), an assessment of any correlation between EMRR and the initiation and development of various kinds of cancers still needs further investigation. A better understanding of the EMRR exposure pattern is an important aspect of such studies [25].
Other non-cancer potential health hazards related to EMRR exposure were also reported. For example, investigations of health hazards among workers in radiotelevision broadcasting centres (exposed to EMRR from the frequency range $88-1000 \mathrm{MHz}$ and maximum E-field from the range $2-55 \mathrm{~V} / \mathrm{m}$ ) have shown that arteriotony, a concentration of cholesterol and a fraction of low density lipoproteins (LDL) were significantly higher in groups of exposed workers, and even systolic blood pressure depended on the level of exposure [26,27].

Such a cumulative scientific background indicates the need to take action to prevent any adverse health effects of electromagnetic radiation exposure among workers and the general public. It poses a challenge to public health experts to understand the nature of EMRR-related health hazards, and to identify the most efficient tools to eliminate them. An important but difficult aspect of activities in that field is the identification of dominant sources of EMRR affecting a particular workplace or space accessible to the general public, such as, for example, offices, schools and libraries - where both workers and members of the general public, including children, may spend many hours a day. An additional difficult task is identification of dominant sources of exposure along the dynamic changes of wireless communication technologies over the years resulting in the reorganisation of both the frequency pattern of emitted EMRR as well as location and technical parameters of transmitting antennas.

The use of the exposimetric technique is an important tool in the further development of scientific background for considerations regarding the possible health effects of environmental EMRR exposure. Exposimeters are functional tools in the exposure evaluating process, but it is necessary to take into consideration the limitations regarding measurement accuracy - e.g., the influence of the body on the measurement result caused by the already mentioned "shadow effect," especially when exposure levels are evaluated against exposure limits established with regard to 
an unperturbed electric field $[13,14,16]$. The use of sufficient correction factors may reduce any misinterpretations of the results of measurements performed by exposimeters [28]. Their small dimensions and weight make exposimeters ideal for individual monitoring in working or living environment. Currently available frequency-selective exposimeters have a relatively small dynamic measurement range, and their use in the working environment (exposed to EMRR many times higher than in the living environment) is problematic. As a result, in the majority of cases today, the occupational exposure near EMRR sources can be only assessed by broadband exposimeters. The further development of this type of measuring device is keenly anticipated in order to be fully applicable for monitoring workers' exposure. The further availability of such exposimeters would also widen the use of this exposure assessment technique in the compliance testing of workers' exposure limits, such as Directive 2013/35/EU or the national occupational labour law.

\section{CONCLUSIONS}

Measurements with the use of broadband and frequencyselective exposimeters belong to research methods applicable in environmental investigations of EMRR exposure. The availability of EMRR frequency-selective exposimeters means that personal complex exposure to electromagnetic radiation from multiple sources can be evaluated with respect to the type of EMRR sources contributing to the total exposure, and their relative contributions, and monitoring exposure variations over time as well.

The use of the exposimetric technique of measurements may lead to establishing a correlation between the level of exposure and EMRR sources influencing an evaluated workplace. Presented frequency-selective measurements show significant differences regarding dominant sources of indoor EMRR exposure in various types of location. The location in urban and rural areas is a key factor differentiating exposure levels. Exposure in the UMTS frequency range is significantly lower than in the GSM system.

Investigations performed in the buildings in urban and rural areas demonstrated the practical applicability of this kind of measuring technique for evaluating the parameters of workers' exposure over both frequency and time.

\section{REFERENCES}

1. World Health Organization. Environmental health criteria 137. Electromagnetic fields $(300 \mathrm{~Hz}-300 \mathrm{GHz})$. Geneva; 1993 [cited 2014 Jun 11]. Available from: http://www. inchem.org/documents/ehc/ehc/ehc137.htm.

2. Vecchia P, Matthes R, Ziegelberger G, Lin J, Saunders R, Swerdlow A, editors. International Commission on Non-Ionizing Radiation Protection. Exposure to high frequency electromagnetic fields, biological effects and health consequences $(100 \mathrm{kHz}-300 \mathrm{GHz})$. Review of the scientific evidence on dosimetry, biological effects, epidemiological observations, and health consequences concerning exposure to high frequency electromagnetic fields (100 kHz to $300 \mathrm{GHz}$ ). Munich; 2009 [cited 2014 Jun 11]. Available from: http://www.emf.ethz.ch/ archive/var/ICNIRP_effekte_RFReview.pdf.

3. International Commission on Non-Radiation Protection. Guidelines for limiting exposure to time-varying electric, magnetic, and electromagnetic fields (up to $300 \mathrm{GHz}$ ). Health Physics. 1998;74(4):494-522.

4. Hansson Mild K, Alanko T, Decat G, Falsaperla R, Gryz K, Hietanen M, et al. Exposure of workers to electromagnetic fields. A review of open questions on exposure assessment techniques. Int J Occup Saf Ergon. 2009;15(1):3-33.

5. Karpowicz J, Gryz K. Practical aspects of occupational EMF exposure assessment. Environmentalist. 2007;27:525-31, http://dx.doi.org/10.1007/s10669-007-9067-y.

6. Karpowicz J, Hietanen M, Gryz K. EU Directive, ICNIRP guidelines and Polish legislation on electromagnetic fields. Int J Occup Saf Ergon. 2006;12(2):125-36. 
7. Ahlbom A, Feychting M, Green A, Khefits L, Savitz DA, Swerdlow AJ; International Commission on Non-Ionizing Radiation Protection Standing Committee on Epidemiology. Epidemiology evidence on mobile phones and tumor risk: A review. Epidemiology. 2009;20(5):639-52.

8. INTERPHONE Study Group. Brain tumour risk in relation to mobile telephone use: Results of the INTERPHONE international case-control study. Int J Epidemiol. 2010 Jun;39(3):675-94, http://dx.doi.org/10.1093/ije/dyq079.

9. Hardell L, Carlberg M, Söderqvist F, Hansson Mild K. Meta-analysis of long-term mobile phone use and the association with brain tumours. Int J Oncol. 2008;32(5):1097-103.

10. Bortkiewicz A, Gadzicka E, Szymczak W, Zmyślony M. Change in tympanic temperature during the exposure to electromagnetic fields emitted by mobile phone. Int J Occup Med Environ Health. 2012;25(2):145-50, http://dx.doi. org/10.2478/S13382-012-0013-y.

11. Scientific Committee on Emerging and Newly Identified Health Risks. Health effects of exposure to EMF. Opinion adopted at the 28th plenary; 2009 Jan 19; Brussels, Belgium [cited 2014 Jun 11]. Available from: http://ec.europa.eu/health/ ph_risk/committees/04_scenihr/docs/scenihr_o_022.pdf.

12. International Agency for Research on Cancer. Non-ionizing radiation, part 2: Radiofrequency electromagnetic fields. Volume 102. IARC Monographs on the evaluation of carcinogenic risks to humans. Lyon: IARC; 2013. p. 1-460.

13. Neubauer G, Cecil S, Giczi W, Petric B, Preiner P, Frohlich J, et al. The association between exposure determined by radiofrequency personal exposimeters and human exposure: A simulation study. Bioelectromagnetics. 2010;31(7):535-45.

14. Röösli M, Frei P, Bolte J, Neubauer G, Cardis E, Feychting $\mathrm{M}$, et al. Conduct of a personal radiofrequency electromagnetic field measurement study: Proposed study protocol. Environ Health. 2010;9:23, http://dx.doi.org/10.1186/1476069X-9-23.

15. Gryz K, Karpowicz J, Leszko W. [Exposimeters of radiofrequency electromagnetic radiation - An overview of functional and technical parameters]. Bezpiecz Pr. 2012;2:12-5. Polish.
16. Gryz K, Zradziński P, Karpowicz J. The role of the location of personal exposimeters on the human body in their use for assessing exposure to electromagnetic field in the radiofrequency range $98-2450 \mathrm{MHz}$ and compliance analysis Evaluation by virtual measurements. BioMedical Research International. Forthcoming.

17. Council of the European Union Recommendation of $12 \mathrm{Ju}$ ly 1999 on the limitation of exposure of the general public to electromagnetic fields (0 Hz to $300 \mathrm{GHz}$ ). 1999/519/EC, Off J Eur Union. 1999;L 199/59.

18. Directive 2013/35/EC of the European Parliament and of the Council of 26 June 2013 on the minimum health and safety requirements regarding the exposure of workers to the risks arising from physical agents (electromagnetic fields) (20th individual Directive within the meaning of Article 16(1) of Directive 89/391/EEC) and repealing Directive 2004/40/EC. Off J Eur Union. 2013;L 179/1.

19. [Regulation of the Minister of Environment of 30 October 2003 on maximum admissible levels of electromagnetic fields in the environment and methods of checking adherence to these levels. J Laws 2003, No. 192, item 1883 (October 30, 2003)]. Polish.

20. Stam R. Comparison of international policies on electromagnetic fields (power frequency and radiofrequency fields) Bilthoven, Netherlands: National Institute for Public Health and the Environment; 2011 [cited 2014 Jun 11]. Available from:http:/ec.europa.eu/health/electromagnetic_fields/docs/ emf_comparision_policies_en.pdf.

21. [Prime Minister decree July 8, 2003. Setting of the exposure limits, of the attention values and of the quality goals for the safety of the general public from exposure to produced electric, magnetic and EMF in the frequency range $100 \mathrm{kHz}$ - $300 \mathrm{GHz}$. Italian Official Gazette, No. 199 (August 28, 2003)]. Italian.

22. [Ordinance relating to Protection from Non Ionizing Radiation (ONIR)]. Switzerland; 1999 [cited 2014 Jun 11]. French. Available from: http://www.admin.ch/ch/f/ rs/8/814.710.fr.pdf. 
23. Information and Communication Technologies Authority (BTK) Regulation on Electromagnetic Exposure. The limit values of the electromagnetic field force from the fixed tele-communication devices operating within the frequency range of $10 \mathrm{kHz}-60 \mathrm{GHz}$ [cited 2014 Jun 11]. Available from: http://eng.btk.gov.tr/mevzuat/yonetmelikler/dosyalar/ By-Law\%20On\%20Determination,\%20Control\%20And $\% 20$ Inspection $\% 20$ Of $\% 20$ The $\% 20$ Limit $\% 20$ Values $\% 20$ Of $\% 20$ Electromagnetic $\% 20$ Field $\% 20$ Force $\% 20$ From $\% 20$ The $\% 20$ Electronic $\% 20$ Communication $\% 20$ Devices $\% 20$ According $\% 20 \mathrm{To} \% 20$ International $\% 20$ Standards.pdf.

24. European Parliament resolution of 2 April 2009 on health concerns associated with electromagnetic fields (2008/2211(INI)) [cited 2014 Jun 11]. Available from: http://www.europarl.europa.eu/sides/getDoc.do?pubRef=-//EP//NONSGML+TA+P6TA-2009-0216+0+DOC+PDF+V0//EN.
25. World Health Organization. WHO research agenda for radio frequency fields. Geneva: WHO; 2010 [cited 2014 Jun 11]. Available from: http://whqlibdoc.who.int/publications/2010/9789241599948_eng.pdf.

26. Vangelova K, Deyanov C, Israel M. Cardiovascular risk in operators under radiofrequency electromagnetic radiation. Int J Hyg Environ Health. 2009;209(2):133-8.

27. Bortkiewicz A, Gadzicka E, Szymczak W, Zmyślony M. Heart rate variability (HRV) analysis in radio and TV broadcasting station workers. Int J Occup Med Environ Health. 2012;25(2):446-55, http://dx.doi.org/10.2478/s13382012-0059-x.

28. Bolte J, van der Zande G, Kamer J. Calibration and uncertainties in personal exposure measurements of radiofrequency electromagnetic fields. Bioelectromagnetics. 2011;32:852-63, http://dx.doi.org/10.1002/bem.20677.

This work is available in Open Access model and licensed under a Creative Commons Attribution-NonCommercial 3.0 Poland License - http://creativecommons.org/ licenses/by-nc/3.0/pl/deed.en. 